\title{
A Narrative Review of the Gut Microbiota and Its Association with Diseases
}

\author{
Dublin Nashin* \\ Department of Microbiology, Savitribai Phule Pune University, Ganeshkhind Rd, Ganeshkhind, Pune, Maharashtra 411007, India \\ *: All correspondence should be sent to: Dr. Dublin Nashin. \\ Author's Contact: Dublin Nashi, PhD, E-mail: dublin.nashi@gmail.com \\ DOl: https://doi.org/10.15354/si.22.re016 \\ The author declares no competing interest.
}

The gut microbiota is vast and diverse, and it is inextricably linked to and interacts with the host. Numerous diseases are associated with the gut microbiota of their occurrence, progression, and prognosis. The gut microbiota has an effect on the occurrence and progression of metabolic diseases through regulating the metabolism of carbohydrates, lipids, and amino acids. Disruptions in the intestinal flora can also contribute to inflammatory bowel disease and certain types of intestinal cancer. Additionally, illnesses of the neuropsychiatric, cardiovascular, and urinary systems, among others, are all associated with the gut microbiota. It is vital to understand the link between gut microbiota and disease in order to prevent, cure, and maintain good health.

Keywords: Gut Microbiota; Metabolic Diseases; Inflammatory Bowel Disease; Neuronal Dysfunction; Cardiovascular Diseases

Science Insights, 2022 February 28; Vol. 40, No. 3, pp.435-441.

(c) 2022 Insights Publisher. All rights reserved.

Creative Commons Non Commercial CC BY-NC: This article is distributed under the terms of the Creative Commons Attribution-NonCommercial 4.0 License which permits non-commercial use, reproduction and distribution of the work without further permission provided the original work is attributed by the Insights Publisher.

$\mathrm{T}$ HE gastrointestinal system contains around 100 trillion microorganisms, including bacteria, viruses, fungus, and protozoa, and is regarded as a virtual organ of the body $(1,2)$. Over three million genes are encoded by the gut microbiome, the collective genomes of the microorganisms that live in the gut and create thousands of metabolites that influence the host's fitness, phenotype, and health (3, 4). A growing body of research indicates that the gut microbiota is intimately linked to human health and the emergence and progression of numerous diseases. Apart from influencing the microecology of the gut, these intestinal flora also influence other bodily systems, helping to maintain them at a particular level of normalcy. The impact of gut microbiota on many human body systems has been steadily uncovered. An imbalanced gut microbiota will result in different system dysfunctions, including those of the neurological and cardiovascular systems $(5,6)$, jeopardizing the body's health. This study examines the relationship between gut microbiota and human diseases with the goal of establishing a foundation for understanding the pathogenesis and treatment of gut microbiota and associated diseases.

\section{Gut Microbiota and Metabolic Diseases}

Studies have established that the gut microbiota plays a critical role in the onset and progression of metabolic disorders $(7,8)$. The gut microbiota interacts with the host to regulate the endocrine system, immunological response, and nervous system function, and dysbiosis results in the development of associated disorders.

\section{Diabetes Mellitus}

Diabetes mellitus (DM) is a metabolic disease that develops as a result of alterations in the gut microbiota, which are important in the regulation of the host's energy metabolism and immunological response (9-11). Diabetes patients' gut microbiota differs 
from that of healthy controls, which has a degree of influence on patients with type 1 (T1DM) or type 2 diabetes (T2DM). Changes in the structure of the gut microbiota can trigger a moderate chronic inflammatory response in the body, resulting in the destruction and death of pancreatic cells and insulin resistance, hence encouraging the onset and progression of T2DM (12). Clinically, glucagon-like peptide-1 (GLP-1)-based medication is frequently used to regulate blood sugar in individuals with type 2 diabetes. In animal models, it has been shown that a certain species of ileal bacteria can suppress the GLP-1-activated gut-brain axis that regulates insulin secretion and stomach emptying (13). Certain gut microbes are involved in the therapeutic effects and adverse reactions of the anti-diabetic drug metformin, and many other clinical drugs for diabetes also increase the number of bacteria that produce short-chain fatty acids by adjusting the composition of the gut microbiota, thereby enhancing the hypoglycemic effect (14). A novel concept is fecal microbiota transplantation (FMT), which may be used in the future as a therapeutic option for diabetes mellitus (15). Animal studies $(16,17)$ have shown that restoring insulin resistance and defective islets in diabetic mice is possible.

\section{Obesity}

The gut microbiota can influence lipopolysaccharide content and short-chain fatty acid synthesis (18), and a prolonged high-sugar, high-fat diet can alter the organization of the gut microbiota (19). The gut microbiota plays a significant role in the onset and progression of obesity by boosting the generation of short-chain fatty acids, suppressing fasting-induced adipose factor (FIAF), modulating persistent moderate inflammatory responses, and limiting fatty acid oxidation (20). In obese individuals, the Firmicutes/Bacteroides ratios were greater, the Bacteroides ratios were lower, and the quantity of Bacteroides polymorpha, a glutamate-fermenting symbiont, was much lower than in lean persons, and was inversely linked with serum glutamate concentrations $(21,22)$. By controlling metabolism, the gut microbiota can influence human obesity, and this impact may be utilized to prevent and cure obesity. When the microbiota of obese mice was transplanted into normally raised mice to alter the recipient mice's gut microbiota and microbiome (23), and the recipient mice were then fed a high-fat diet, the recipient mice's liver metabolism was significantly altered (24), with decreased hepatic gluconeogenesis and glucose-6-phosphatase (G6Pase) activity (25). The microbiota of obese mice has an effect on the metabolism of normal mice, and gut microbiota transplantation from healthy individuals may help prevent and treat obesity (26). Thus, the gut microbiota produces a variety of metabolites such as short-chain fatty acids and lipopolysaccharides by regulating the metabolism of sugar, lipids, and amino acids or by interfering with the metabolism of normal substances, thereby contributing to the occurrence and development of metabolic diseases. Meanwhile, the bacterial structure and species composition of the gut microbiota are influenced by the body's metabolism, and their interaction complicates the relationship between gut microbiota and metabolic illnesses (Figure 1).

\section{Gut Microbiota and Inflammatory Bowel Dis-}

\section{ease}

Ulcerative colitis (UC) and Crohn's disease (CD) are the two most common clinical manifestations of inflammatory bowel disease (IBD). Although CD and UC patients are both high in lactobacilli and bifidobacteri, the Clostridium flexis group in these two diseases is dramatically reduced $(27,28)$, suggesting that probiotics should be administered cautiously in the acute phase of IBD patients. FMT may be utilized as a rescue therapy for refractory inflammatory bowel disease in the treatment of IBD. FMT alone is relatively safe and can have short-term effects in young patients with active inflammatory bowel disease (IBD) (29), although adverse events related with FMT and associated safety concerns have lately raised concerns (30). Additionally, FMT can help infants with allergic colitis by reestablishing their gut microbiota (31). The connection between the gut bacteria and the host is critical for the development of CD and $\operatorname{UC}(32,33)$. As a result, in future IBD treatment trials, the treatment of gut flora will become a focal point (34). Meanwhile, the use of probiotics to treat inflammatory bowel disease is a priority, and has yielded promising results $(35,36)$.

\section{Gut Microbiota and Nervous System and Psy- chiatric Diseases}

Antibiotics, environmental and viral agents, enteric neurotransmitters/neuromodulators, cytokines, and sensory vagal fibers all communicate to the central nervous system (CNS) information regarding the gut's condition (37-41). By activating the hypothalamic-pituitary-adrenal (HPA) axis via sensory nerve fibers and CNS regulatory regions, sensory nerve fibers and CNS regulatory regions can impact the composition of the gut microbiota directly or indirectly via nutritional availability $(42,43)$. There is a distinct difference between the gut microbiota of schizophrenia patients and healthy individuals (44). Prevotellaceae are reduced in the intestinal tracts of patients with Parkinson's disease, and this difference can be used to make an initial diagnosis of Parkinson's disease (45). The diversity of gut microbiota has varying effects on the autonomic nervous system and central nervous system (CNS) via numerous routes such as the enteric nervous system (ENS) and vagus nerve, and also has an effect on the host's mental state $(46,47)$. Transplanting the fecal microbiota of depressed patients into rats with a depleted microbiota resulted in recipient animals developing behavioral and physiological characteristics of depression, including anhedonia, anxiety-like behavior, and altered tryptophan metabolism, demonstrating that the gut microbiota community can influence the host's mood $(48,49)$. Additionally, the gut microbiome plays a critical role in neurodevelopment (50). Emerging data suggests that the development of neurodegenerative disorders such as Alzheimer's disease is inextricably linked to the neuroinflammatory impact of the gut microbiota (51-53). Pain, whether acute or chronic, is a significant issue that has drawn attention to the possible role of gut bacteria in its onset and development $(54,55)$.

\section{Gut Microbiota and Tumor}

Recently, it has been discovered that the gut microbiota is critical for the occurrence, development, prognosis, and disease outcome of intestinal cancers (56-58). At the moment, colon and 


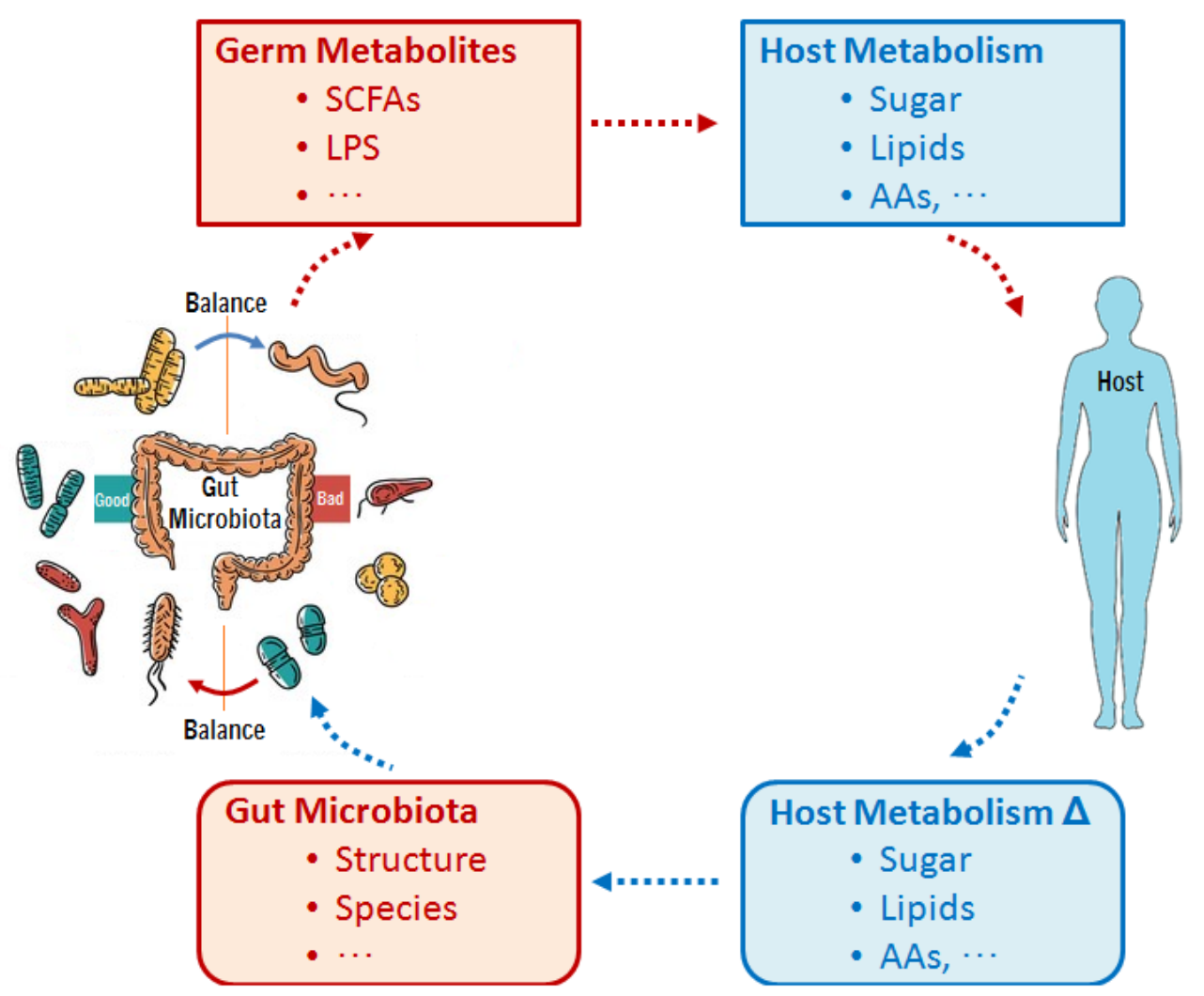

Figure 1. Interaction between Gut Microbiota and Host Metabolism.

rectal cancer staging and prognosis are largely determined by tumor node metastases (TNM) or the Duke System, a crude prognostic guideline that delays the discovery of advanced cancer and has a detrimental effect on the tumor's biological properties (59). The total metabolic profile of colonic mucosa was able to differentiate not only lesions from normal mucosa, but also the morphological and clinicopathological characteristics of colorectal cancer $(60,61)$, which is beneficial for colon tumor early detection and therapy. Apart from intestinal malignancies, gut microbiota can promote the occurrence and development of other types of tumors, including liver cancer (62), pancreatic cancer (63) and breast cancer (64), via metabolic pathways, hormone or brain-gut axis pathways, immunological pathways, and multifunctional pathways. Because disruption of the gut microbiota contributes significantly to the occurrence and development of cancers, may probiotic supplementation contribute to tumor prevention and treatment? Probiotics have been shown in studies to increase the amount and quality of gut microbiota (65), hence lowering chronic inflammation, the occurrence of sexual responses, and the formation of carcinogenic chemicals induced by gut microbiota dysregulation (66). Lactobacillus reuteri can enhance the activity of mitogen-activated protein kinase; inhibit the nuclear factor kappa B pathway; and promote tumor necrosis factor-induced death of myeloid leukemia cells in tumor treatment (67). These findings supported the use of probiotics in the treatment and prevention of cancers.

\section{Gut Microbiota and Cardiovascular Disease}

Gut microbes, like endocrine organs, produce biologically active metabolites via a variety of pathways, including trimethylamine/ trimethylamine $\mathrm{N}$-oxide, short-chain fatty acids, and primary and secondary bile acids $(68,69)$, affecting the host's physiological functions and thus playing a critical role in cardiovascular disease.

\section{Hypertension}

Investigating the gut microbiota of hypertensive individuals revealed that the intestinal flora was much less diverse than that of healthy individuals $(70,71)$, implying that gut microbiota may be associated with hypertension. The gut microbiota has been shown to create short-chain fatty acids via metabolism, so modulating the incidence of hypertension (72), and a high-fiber diet has been shown to alter the makeup of the gut microbiota and its metabolites, thereby lowering blood pressure (73). Of course, the underlying mechanism through which gut microbes contribute to hypertension remains unknown.

\section{Heart Failure}

Certain diseases and the gut microbiome interact in people with heart failure. In a study of the gut microbiota of patients with 
chronic heart failure, it was discovered that patients with congestive heart failure have particular fundamental bacterial imbalances (74). Congestion of the splanchnic circulation, edema of the intestinal wall, and impaired intestinal barrier function all result in bacterial translocation and bacterial products entering the systemic circulation, aggravating the inflammatory response and promoting the progression of heart failure and atherosclerosis (75). The gut microbiota is intimately linked to the onset and progression of cardiovascular disease, or it may be exploited as a novel method of treating cardiovascular disease (76).

\section{Gut Microbiota and Other Diseases}

Apart from the disorders described above, gut microbiota is also strongly associated with the onset, development, and prognosis of a wide variety of other diseases in humans. When $16 \mathrm{~S}$ ribosomal RNA gene sequencing was used to examine the relationship between the gut microbiome and kidney stones, it was discovered that the number of intestinal microbial species decreased in patients with multiple kidney stones (77), and that changes in microbial abundance affect potassium, sodium, and calcium levels in the blood, as well as chlorine and other trace elements, which provides new non-invasive biomarkers for the diagnosis of kidney stones and aids in the search for a way to prevent them (78). Liver illnesses such as alcoholic hepatitis, non-alcoholic fatty liver disease, and cirrhosis are also strongly associated with alterations in the gut microbiota $(79,80)$.

\section{Concluding Remarks}

The gut microbiome and human diseases are inextricably linked. The imbalance of the gut microbiota has a role in the onset and progression of a variety of systemic illnesses. With the advancement of the gut microbiota genome and related biological research, as well as the application of novel research tools, the mechanism by which gut microbiota contribute to the occurrence and progression of various diseases will become increasingly obvious. Utilizing the gut microbiota as a new target will result in a more safe and effective method of illness prevention and treatment, as well as fresh ideas for the development of several new medications, which is critical for the advancement of medicine.m

\section{References}

1. Adak $A$, Khan MR. An insight into gut microbiota and its functionalities. Cell Mol Life Sci 2019; 76(3):473-493. DOI: https://doi.org/10.1007/s00018-018-2943-4

2. Gomaa EZ. Human gut microbiota/microbiome in health and diseases: A review. Antonie Van Leeuwenhoek 2020; 113(12):2019-2040. DOI: https://doi.org/10.1007/s10482-020-01474-7

3. Flint HJ, Scott KP, Louis P, Duncan SH. The role of the gut microbiota in nutrition and health. Nat Rev Gastroenterol Hepatol 2012; 9(10):577-589. DOI: https://doi.org/10.1038/nrgastro.2012.156

4. Valdes AM, Walter J, Segal E, Spector TD. Role of the gut microbiota in nutrition and health. BMJ 2018; 361 :k2179. DOI: https://doi.org/10.1136/bmj.k2179

5. Cryan JF, O'Riordan KJ, Cowan CSM, Sandhu KV, Bastiaanssen TFS, Boehme M, Codagnone MG, Cussotto S, Fulling C, Golubeva AV, Guzzetta KE, Jaggar M, Long-Smith CM, Lyte JM, Martin JA, Molinero-Perez A, Moloney G, Morelli E, Morillas E, O'Connor R, Cruz-Pereira JS, Peterson VL, Rea K, Ritz NL, Sherwin E, Spichak S, Teichman EM, van de Wouw M, Ventura-Silva AP, Wallace-Fitzsimons SE, Hyland N, Clarke G, Dinan TG. The Microbiota-Gut-Brain axis. Physiol Rev 2019; 99(4):1877-2013. DOI: https://doi.org/10.1152/physrev.00018.2018

6. Witkowski M, Weeks TL, Hazen SL. Gut microbiota and cardiovascular disease. Circ Res 2020; 127(4):553-570. DOI: https://doi.org/10.1161/circresaha.120.316242

7. Pascale A, Marchesi N, Marelli C, Coppola A, Luzi L,

Govoni S, Giustina A, Gazzaruso C. Microbiota and metabolic diseases. Endocrine 2018; 61(3):357-371. DOI: https://doi.org/10.1007/s12020-018-1605-5

8. Fan Y, Pedersen O. Gut microbiota in human metabolic health and disease. Nat Rev Microbiol 2021; 19(1):55-71. DOI: https://doi.org/10.1038/s41579-020-0433-9

9. Muñoz-Garach A, Diaz-Perdigones C, Tinahones FJ. Gut microbiota and type 2 diabetes mellitus. Endocrinol Nutr 2016; 63(10):560-568. DOI: https://doi.org/10.1016/i.endonu.2016.07.008. Erratum in: Endocrinol Diabetes Nutr 2017; 64(9):514.

10. Gurung M, Li Z, You H, Rodrigues R, Jump DB, Morgun A, Shulzhenko N. Role of gut microbiota in type 2 diabetes pathophysiology. EBioMedicine 2020; 51:102590. DOI: https://doi.org/10.1016/j.ebiom.2019.11.051

11. Tanase DM, Gosav EM, Neculae E, Costea CF, Ciocoiu M, Hurjui LL, Tarniceriu CC, Maranduca MA, Lacatusu CM, Floria M, Serban IL. Role of gut microbiota on onset and progression of microvascular complications of type 2 diabetes (T2DM). Nutrients 2020; 12(12):3719. DOI: https://doi.org/10.3390/nu12123719

12. Sun J, Furio L, Mecheri R, van der Does AM, Lundeberg E, Saveanu L, Chen $Y$, van Endert $P$, Agerberth B, Diana J. Pancreatic $\beta$-cells limit autoimmune diabetes via an immunoregulatory antimicrobial peptide expressed under the influence of the gut microbiota. Immunity 2015; 43(2):304-317. DOI: https://doi.org/10.1016/j.immuni.2015.07.013

13. Grasset E, Puel A, Charpentier J, Collet X, Christen- 
sen JE, Tercé F, Burcelin R. A specific gut microbiota dysbiosis of type 2 diabetic mice induces GLP-1 resistance through an enteric NO-dependent and gut-brain axis mechanism. Cell Metab 2017; 25(5):1075-1090.e5. DOI:

https://doi.org/10.1016/i.cmet.2017.04.013. Erratum in: Cell Metab 2017; 26(1):278.

14. Sun L, Xie C, Wang G, Wu Y, Wu Q, Wang X, Liu J, Deng $Y$, Xia J, Chen B, Zhang S, Yun C, Lian G, Zhang $X$, Zhang $\mathrm{H}$, Bisson WH, Shi J, Gao X, Ge P, Liu C, Krausz KW, Nichols RG, Cai J, Rimal B, Patterson AD, Wang X, Gonzalez FJ, Jiang C. Gut microbiota and intestinal FXR mediate the clinical benefits of metformin. Nat Med 2018; 24(12):1919-1929. DOI: https://doi.org/10.1038/s41591-018-0222-4

15. Aron-Wisnewsky J, Clément K, Nieuwdorp M. Fecal microbiota transplantation: A future therapeutic option for obesity/diabetes? Curr Diab Rep 2019; 19(8):51. DOI: https://doi.org/10.1007/s11892-019-1180-z

16. Wang H, Lu Y, Yan Y, Tian S, Zheng D, Leng D, Wang C, Jiao J, Wang Z, Bai Y. Promising Treatment for Type 2 Diabetes: Fecal Microbiota Transplantation Reverses Insulin Resistance and Impaired Islets. Front Cell Infect Microbiol 2020; 9:455. DOI: https://doi.org/10.3389/fcimb.2019.00455

17. Zhang PP, Li LL, Han X, Li QW, Zhang XH, Liu JJ, Wang Y. Fecal microbiota transplantation improves metabolism and gut microbiome composition in $\mathrm{db} / \mathrm{db}$ mice. Acta Pharmacol Sin 2020; 41(5):678-685. DOI: https://doi.org/10.1038/s41401-019-0330-9

18. Morrison DJ, Preston T. Formation of short chain fatty acids by the gut microbiota and their impact on human metabolism. Gut Microbes. 2016; 7(3):189-200. DOI: https://doi.org/10.1080/19490976.2015.1134082

19. Murphy EA, Velazquez KT, Herbert KM. Influence of high-fat diet on gut microbiota: A driving force for chronic disease risk. Curr Opin Clin Nutr Metab Care 2015; 18(5):515-520. DOI: https://doi.org/10.1097/mco.0000000000000209

20. Khan MJ, Gerasimidis K, Edwards CA, Shaikh MG. Role of gut microbiota in the aetiology of obesity: Proposed mechanisms and review of the literature. J Obes 2016; 2016:7353642. DOI: https://doi.org/10.1155/2016/7353642

21. Clarke SF, Murphy EF, Nilaweera K, Ross PR, Shanahan F, O'Toole PW, Cotter PD. The gut microbiota and its relationship to diet and obesity: New insights. Gut Microbes 2012; 3(3):186-202. DOI: https://doi.org/10.4161/gmic.20168

22. Magne F, Gotteland M, Gauthier L, Zazueta A, Pesoa $S$, Navarrete P, Balamurugan R. The Firmicutes/Bacteroidetes ratio: A relevant marker of gut dysbiosis in obese patients? Nutrients 2020; 12(5):1474. DOI: https://doi.org/10.3390/nu12051474

23. Ellekilde M, Selfjord E, Larsen CS, Jakesevic M, Rune I, Tranberg B, Vogensen FK, Nielsen DS, Bahl MI, Licht TR, Hansen AK, Hansen $\mathrm{CH}$. Transfer of gut microbiota from lean and obese mice to antibiotic-treated mice. Sci Rep 2014; 4:5922. DOI: https://doi.org/10.1038/srep05922

24. Nicolas S, Blasco-Baque V, Fournel A, Gilleron J,
Klopp P, Waget A, Ceppo F, Marlin A, Padmanabhan R, lacovoni JS, Tercé F, Cani PD, Tanti JF, Burcelin R, Knauf C, Cormont M, Serino M. Transfer of dysbiotic gut microbiota has beneficial effects on host liver metabolism. Mol Syst Biol 2017; 13(3):921. DOI: https://doi.org/10.15252/msb.20167356

25. Trinh KY, O'Doherty RM, Anderson P, Lange AJ, Newgard CB. Perturbation of fuel homeostasis caused by overexpression of the glucose-6-phosphatase catalytic subunit in liver of normal rats. J Biol Chem 1998; 273(47):31615-31620. DOI: https://doi.org/10.1074/jbc.273.47.31615

26. Aoun A, Darwish F, Hamod N. the influence of the gut microbiome on obesity in adults and the role of probiotics, prebiotics, and synbiotics for weight loss. Prev Nutr Food Sci 2020; 25(2):113-123. DOI: https://doi.org/10.3746/pnf.2020.25.2.113

27. Wang W, Chen L, Zhou R, Wang X, Song L, Huang S, Wang G, Xia B. Increased proportions of Bifidobacterium and the Lactobacillus group and loss of butyrate-producing bacteria in inflammatory bowel disease. J Clin Microbiol 2014; 52(2):398-406. DOI: https://doi.org/10.1128/jcm.01500-13

28. Saez-Lara MJ, Gomez-Llorente C, Plaza-Diaz J, Gil A. The role of probiotic lactic acid bacteria and bifidobacteria in the prevention and treatment of inflammatory bowel disease and other related diseases: A systematic review of randomized human clinical trials. Biomed Res Int 2015; 2015:505878. DOI: https://doi.org/10.1155/2015/505878

29. Goyal A, Yeh A, Bush BR, Firek BA, Siebold LM, Rogers MB, Kufen AD, Morowitz MJ. Safety, clinical response, and microbiome findings following fecal microbiota transplant in children with inflammatory bowel disease. Inflamm Bowel Dis 2018; 24(2):410-421. DOI: https://doi.org/10.1093/ibd/izx035

30. Park SY, Seo GS. Fecal microbiota transplantation: Is it safe? Clin Endosc 2021; 54(2):157-160. DOI: https://doi.org/10.5946/ce.2021.072

31. Liu SX, Li YH, Dai WK, Li XS, Qiu CZ, Ruan ML, Zou B, Dong C, Liu YH, He JY, Huang ZH, Shu SN. Fecal microbiota transplantation induces remission of infantile allergic colitis through gut microbiota re-establishment. World J Gastroenterol 2017; 23(48):8570-8581. DOI: https://doi.org/10.3748/wig.v23.i48.8570

32. Zhang M, Sun K, Wu Y, Yang Y, Tso P, Wu Z. Interactions between Intestinal Microbiota and Host Immune Response in Inflammatory Bowel Disease. Front Immunol 2017; 8:942. DOI: https://doi.org/10.3389/fimmu.2017.00942

33. Shen ZH, Zhu CX, Quan YS, Yang ZY, Wu S, Luo WW, Tan B, Wang XY. Relationship between intestinal microbiota and ulcerative colitis: Mechanisms and clinical application of probiotics and fecal microbiota transplantation. World J Gastroenterol 2018; 24(1):5-14. DOI: https://doi.org/10.3748/wig.v24.i1.5

34. Khan I, Ullah N, Zha L, Bai Y, Khan A, Zhao T, Che T, Zhang $\mathrm{C}$. Alteration of gut microbiota in inflammatory bowel disease (IBD): cause or consequence? IBD treatment targeting the gut microbiome. Pathogens 
2019; 8(3):126. DOI:

https://doi.org/10.3390/pathogens8030126

35. Jonkers D, Stockbrügger R. Probiotics and inflammatory bowel disease. J R Soc Med 2003; 96(4):167-171.

36. Jakubczyk D, Leszczyńska K, Górska S. the effectiveness of probiotics in the treatment of inflammatory bowel disease (IBD)-A critical review. Nutrients 2020; 12(7):1973. DOI: https://doi.org/10.3390/nu12071973

37. Karakan T, Ozkul C, Küpeli Akkol E, Bilici S, Sobarzo-Sánchez E, Capasso R.

Gut-brain-microbiota axis: antibiotics and functional gastrointestinal disorders. Nutrients 2021; 13(2):389. DOI: https://doi.org/10.3390/nu13020389

38. Wang Y, Wang Z, Wang Y, Li F, Jia J, Song X, Qin S, Wang R, Jin F, Kitazato K, Wang Y. The gut-microglia connection: implications for central nervous system diseases. Front Immunol 2018; 9:2325. DOI: https://doi.org/10.3389/fimmu.2018.02325

39. Jacobson A, Yang D, Vella M, Chiu IM. The intestinal neuro-immune axis: Crosstalk between neurons, immune cells, and microbes. Mucosal Immunol 2021; 14(3):555-565. DOI: https://doi.org/10.1038/s41385-020-00368-1

40. Yu CD, Xu QJ, Chang RB. Vagal sensory neurons and gut-brain signaling. Curr Opin Neurobiol 2020; 62:133-140. DOI: https://doi.org/10.1016/j.conb.2020.03.006

41. Breit S, Kupferberg A, Rogler G, Hasler G. Vagus nerve as modulator of the brain-gut axis in psychiatric and inflammatory disorders. Front Psychiatry 2018; 9:44. DOI: https://doi.org/10.3389/fpsyt.2018.00044

42. Appleton J. The gut-brain axis: Influence of microbiota on mood and mental health. Integr Med (Encinitas) 2018; 17(4):28-32.

43. Carabotti M, Scirocco A, Maselli MA, Severi C. The gut-brain axis: Interactions between enteric microbiota, central and enteric nervous systems. Ann Gastroenterol 2015; 28(2):203-209. Erratum in: Ann Gastroenterol 2016; 29(2):240.

44. Szeligowski T, Yun AL, Lennox BR, Burnet PWJ. The gut microbiome and schizophrenia: The current state of the field and clinical applications. Front Psychiatry 2020; 11:156. DOI: https://doi.org/10.3389/fpsyt.2020.00156

45. Haikal C, Chen QQ, Li JY. Microbiome changes: An indicator of Parkinson's disease? Transl Neurodegener 2019; 8:38. DOI: https://doi.org/10.1186/s40035-019-0175-7

46. Mohajeri MH, La Fata G, Steinert RE, Weber P. Relationship between the gut microbiome and brain function. Nutr Rev 2018; 76(7):481-496. DOI: https://doi.org/10.1093/nutrit/nuy009

47. Ma Q, Xing C, Long W, Wang HY, Liu Q, Wang RF. Impact of microbiota on central nervous system and neurological diseases: The gut-brain axis. J Neuroinflammation 2019 Mar 1; 16(1):53. DOI: https://doi.org/10.1186/s12974-019-1434-3

48. Kelly JR, Borre Y, O' Brien C, Patterson E, El Aidy S, Deane J, Kennedy PJ, Beers S, Scott K, Moloney G, Hoban AE, Scott L, Fitzgerald P, Ross P, Stanton C,
Clarke G, Cryan JF, Dinan TG. Transferring the blues: Depression-associated gut microbiota induces neurobehavioural changes in the rat. J Psychiatr Res 2016; 82:109-118. DOI: https://doi.org/10.1016/i.jpsychires.2016.07.019

49. Knudsen JK, Michaelsen TY, Bundgaard-Nielsen C, Nielsen RE, Hjerrild S, Leutscher P, Wegener G, Sørensen S. Faecal microbiota transplantation from patients with depression or healthy individuals into rats modulates mood-related behaviour. Sci Rep 2021; 11(1):21869. DOI:

https://doi.org/10.1038/s41598-021-01248-9

50. Tognini P. Gut microbiota: A potential regulator of neurodevelopment. Front Cell Neurosci 2017; 11:25 DOI: https://doi.org/10.3389/fncel.2017.00025

51. Jiang C, Li G, Huang P, Liu Z, Zhao B. The gut microbiota and Alzheimer's disease. J Alzheimers Dis 2017; 58(1):1-15. DOI: https://doi.org/10.3233/jad-161141

52. Giau VV, Wu SY, Jamerlan A, An SSA, Kim SY, Hulme J. Gut microbiota and their neuroinflammatory implications in Alzheimer's disease. Nutrients 2018; 10(11):1765. DOI: https://doi.org/10.3390/nu10111765

53. Kesika P, Suganthy N, Sivamaruthi BS, Chaiyasut C. Role of gut-brain axis, gut microbial composition, and probiotic intervention in Alzheimer's disease. Life Sci 2021; 264:118627. DOI: https://doi.org/10.1016/j.Ifs.2020.118627

54. Brenner D, Shorten GD, O'Mahony SM. Postoperative pain and the gut microbiome. Neurobiol Pain $2021 ; 10: 100070$. DOI: https://doi.org/10.1016/i.ynpai.2021.100070

55. Guo R, Chen LH, Xing C, Liu T. Pain regulation by gut microbiota: Molecular mechanisms and therapeutic potential. Br J Anaesth 2019; 123(5):637-654. DOI: https://doi.org/10.1016/i.bja.2019.07.026

56. Lin C, Cai X, Zhang J, Wang W, Sheng Q, Hua H, Zhou X. Role of gut microbiota in the development and treatment of colorectal cancer. Digestion 2019; 100(1):72-78. DOI: https://doi.org/10.1159/000494052

57. Zhou $\mathrm{H}$, Yuan $\mathrm{Y}$, Wang $\mathrm{H}$, Xiang $\mathrm{W}$, Li S, Zheng $\mathrm{H}$, Wen Y, Ming Y, Chen L, Zhou J. Gut microbiota: A potential target for cancer interventions. Cancer Manag Res 2021; 13:8281-8296. DOI: https://doi.org/10.2147/CMAR.S328249

58. Li L, Li X, Zhong W, Yang M, Xu M, Sun Y, Ma J, Liu T, Song X, Dong W, Liu X, Chen Y, Liu Y, Abla Z, Liu W, Wang B, Jiang K, Cao H. Gut microbiota from colorectal cancer patients enhances the progression of intestinal adenoma in Apcmin/+ mice. EBioMedicine 2019; 48:301-315. DOI: https://doi.org/10.1016/i.ebiom.2019.09.021. Erratum in: EBioMedicine 2020; 53:102680.

59. Wu JS. Rectal cancer staging. Clin Colon Rectal Surg 2007; 20(3):148-157. DOI: https://doi.org/10.1055/s-2007-984859

60. Kinross J, Mirnezami R, Alexander J, Brown R, Scott A, Galea D, Veselkov K, Goldin R, Darzi A, Nicholson J, Marchesi JR. A prospective analysis of mucosal microbiome-metabonome interactions in colorecta 
cancer using a combined MAS $1 \mathrm{HNMR}$ and metataxonomic strategy. Sci Rep 2017; 7(1):8979. DOI: https://doi.org/10.1038/s41598-017-08150-3

61. Papagiorgis PC, Zizi AE, Tseleni S, Oikonomakis IN Nikiteas NI. Clinicopathological differences of colorectal cancers according to tumor origin: Identification of possibly de novo lesions. Biomed Rep 2013; 1(1):97-104. DOI: https://doi.org/10.3892/br.2012.17

62. Yu LX, Schwabe RF. The gut microbiome and liver cancer: mechanisms and clinical translation. Nat Rev Gastroenterol Hepatol 2017; 14(9):527-539. DOI: https://doi.org/10.1038/nrgastro.2017.72

63. Li Q, Jin M, Liu Y, Jin L. Gut microbiota: Its potential roles in pancreatic cancer. Front Cell Infect Microbiol 2020; 10:572492. DOI: https://doi.org/10.3389/fcimb.2020.572492

64. Laborda-Illanes A, Sanchez-Alcoholado L, Dominguez-Recio ME, Jimenez-Rodriguez B, Lavado R, Comino-Méndez I, Alba E, Queipo-Ortuño MI. Breast and gut microbiota action mechanisms in breast cancer pathogenesis and treatment. Cancers (Basel) 2020; 12(9):2465. DOI: https://doi.org/10.3390/cancers12092465

65. Wang X, Zhang P, Zhang X. Probiotics regulate gut microbiota: An effective method to improve immunity. Molecules 2021; 26(19):6076. DOI: https://doi.org/10.3390/molecules26196076

66. Vivarelli S, Salemi R, Candido S, Falzone L, Santagati M, Stefani S, Torino F, Banna GL, Tonini G, Libra M. Gut microbiota and cancer: From pathogenesis to therapy. Cancers (Basel) 2019; 11(1):38. DOI: https://doi.org/10.3390/cancers11010038

67. Iyer $C$, Kosters A, Sethi G, Kunnumakkara AB, Aggarwal BB, Versalovic J. Probiotic Lactobacillus reuteri promotes TNF-induced apoptosis in human myeloid leukemia-derived cells by modulation of NF-kappaB and MAPK signalling. Cell Microbiol 2008; 10(7):1442-1452. DOI: https://doi.org/10.1111/j.1462-5822.2008.01137.x

68. Brown JM, Hazen SL. The gut microbial endocrine organ: bacterially derived signals driving cardiometabolic diseases. Annu Rev Med 2015; 66:343-359. DOI: https://doi.org/10.1146/annurev-med-060513-093205

69. Wang B, Qiu J, Lian J, Yang X, Zhou J. Gut metabolite trimethylamine- $\mathrm{N}$-oxide in atherosclerosis: From mechanism to therapy. Front Cardiovasc Med 2021; 8:723886. DOI: https://doi.org/10.3389/fcvm.2021.723886

70. Avery EG, Bartolomaeus H, Maifeld A, Marko L, Wiig $\mathrm{H}$, Wilck N, Rosshart SP, Forslund SK, Müller DN. The gut microbiome in hypertension: Recent ad- vances and future perspectives. Circ Res 2021; 128(7):934-950. DOI:

https://doi.org/10.1161/circresaha.121.318065

71. Louca P, Nogal A, Wells PM, Asnicar F, Wolf J, Steves CJ, Spector TD, Segata N, Berry SE, Valdes AM, Menni C. Gut microbiome diversity and composition is associated with hypertension in women. $J$ Hypertens 2021; 39(9):1810-1816. DOI: https://doi.org/10.1097/hih.0000000000002878

72. Pluznick JL. Microbial short-chain fatty acids and blood pressure regulation. Curr Hypertens Rep 2017; 19(4):25. DOI: https://doi.org/10.1007/s11906-017-0722-5

73. Marques FZ, Nelson E, Chu PY, Horlock D, Fiedler A, Ziemann M, Tan JK, Kuruppu S, Rajapakse NW, El-Osta A, Mackay CR, Kaye DM. High-fiber diet and acetate supplementation change the gut microbiota and prevent the development of hypertension and heart failure in hypertensive mice. Circulation 2017; 135(10):964-977. DOI: https://doi.org/10.1161/circulationaha.116.024545

74. Beale AL, O'Donnell JA, Nakai ME, Nanayakkara S, Vizi D, Carter K, Dean E, Ribeiro RV, Yiallourou S, Carrington MJ, Marques FZ, Kaye DM. The gut microbiome of heart failure with preserved ejection fraction. J Am Heart Assoc 2021; 10(13):e020654. DOI: https://doi.org/10.1161/iaha.120.020654

75. Ahmad AF, Ward NC, Dwivedi G. The gut microbiome and heart failure. Curr Opin Cardiol 2019; 34(2):225-232. DOI: https://doi.org/10.1097/hco.0000000000000598

76. Branchereau M, Burcelin R, Heymes $C$. The gut microbiome and heart failure: $A$ better gut for a better heart. Rev Endocr Metab Disord 2019; 20(4):407-414. DOI: https://doi.org/10.1007/s11154-019-09519-7

77. Tang R, Jiang Y, Tan A, Ye J, Xian X, Xie Y, Wang Q, Yao Z, Mo Z. 16S rRNA gene sequencing reveals altered composition of gut microbiota in individuals with kidney stones. Urolithiasis 2018; 46(6):503-514. DOI: https://doi.org/10.1007/s00240-018-1037-y

78. Stanford J, Charlton K, Stefoska-Needham A, Ibrahim R, Lambert K. The gut microbiota profile of adults with kidney disease and kidney stones: A systematic review of the literature. BMC Nephrol 2020;21(1):215 DOI: https://doi.org/10.1186/s12882-020-01805-w

79. Kwong EK, Puri P. Gut microbiome changes in nonalcoholic fatty liver disease \& alcoholic liver disease. Transl Gastroenterol Hepatol 2021; 6:3. DOI: https://doi.org/10.21037/tgh.2020.02.18

80. Lee NY, Suk KT. The role of the gut microbiome in liver cirrhosis treatment. Int J Mol Sci 2020; 22(1):199. DOI: https://doi.org/10.3390/ijms22010199 